\title{
Advanced Microcontroller Based Bio-Metric Authentication Voting Machine
}

\author{
B.FarhathAnjum ${ }^{1}$ M.Deepa ${ }^{2}$ Mrs.C.N.Kalaivani \\ M. E (Asst.Professor) 1 and 2 U.G students \\ 1(ECE,Dhaanish Ahmed College Of Engineering,Chennai) \\ 2(ECE,Dhaanish Ahmed College Of Engineering,Chennai)
}

\begin{abstract}
Biometric voting has made the voting procedure simpler. It is a revolutionary method preferred to traditional EVM voting as it is risk defective. It is advantageous because it includes features such as voters can able to caste their votes globally, reduction of counting time, expenditure incurred on man power deployment and carrying of photo id cards for recognition. Stored finger prints are retained even in the event of complete power failure or battery drain. He/she grants permission to the voters to vote their selected candidates if the finger print are recognized. Each person can vote for one candidate only. Finally results are being displayed, when the polling officer enters the password.
\end{abstract}

\section{Keywords: - Arduino microcontroller, ATmega328,FingerPrintmodule, Visual basics}

\section{INTRODUCTION}

Electronic Voting Machines ("EVM") are being used in Indian General and State Elections to implement electronic voting in part from 1999 elections and in total since 2002 elections. The EVMs reduce the time in both casting a vote and declaring the results compared to the old paper ballot system. The EVMs were devised and designed by Election Commission of India in collaboration with two Public Sector undertakings viz., Bharat Electronics Limited, Bangalore and Electronics Corporation of India Limited, Hyderabad. The EVMs are now manufactured by the above two undertakings. EVMs were first used in 1982 in the by-election to Parur Assembly Constituency of Kerala for a limited number of polling stations (50 polling stations.

Voting is the bridge between the governed and government. The last few years have brought a renew focus onto the technology used in the voting process and a hunt for voting machines. Computerized voting systems bring improved usability and cost benefits but suffer from weak software which has lot of bugs. When scrutinized, current voting systems have security holes and it becomes difficult to prove even simple security properties about them. A voting system that can be proven correct would solve many problems. High security is essential to elections. There has been a lot of attention to an electronic voting by cryptographers. Many scientific researches have been done in order to achieve security, privacy and correctness in electronic voting systems by improving cryptographic protocols of e-voting systems. Currently, the practical security in e-voting systems is more important than the use of cryptographic schemes .One of the main interests is seemingly contradicting security properties. On one hand, voting must be private and the votes should be anonymous. On the other hand, voters must be identified in order to guarantee that only the eligible voters are capable to vote. Hence, e-voting should be uniform, confidential, secure and verifiable. The most important requirements for e-voting can be characterized as:

- Eligible voter is authenticated by his/her unique characteristics.

- Eligible voters are not allowed to cast more than one vote.

- Votes are secret.

- Auditors can check whether all correct cast ballot participated in the computation of the final tally.

- Result of election should be secret until the end Of an election.

- While voting is on, there should not be a method of knowing intermediate result that can affect the remaining voter's decisions

- All valid votes must be counted correctly and the system outputs the final tally.

- It must be possible to repeat the computation of the final tally.

The following three dimensions are used to make a comparison of electronic voting systems for various nations

- Whether a country's system uses a paper audit trail.

- Whether the system permits an anonymous, blank or spoiled ballot.

- Whether the software is open source or proprietary. 
We have proposed a model for e-voting based on biometric technique. Biometrics has been widely used in various applications such as criminal identification, prison security electronic banking, ecommerce .Biometric authentication requires comparing a registered or enrolled biometric sample (biometric template or identifier) against a newly captured biometric sample (for example, a fingerprint captured during a login). During enrollment, a sample of the biometric trait is captured, processed by a computer and stored for later comparison. Biometric recognition can be used in identification mode, where the biometric system identifies a person from the entire enrolled population by searching a database for a match based solely on the biometric. A system can also be used in verification mode, where the biometric system authenticates a person's claimed identity from their previously enrolled pattern. This is also called "one-to one" matching. The proposed model uses biometrics in the verification mode during e-voting. we can conclude that the finger print recognition is that fast and accurate biometric technique required for making reliable and secure system .

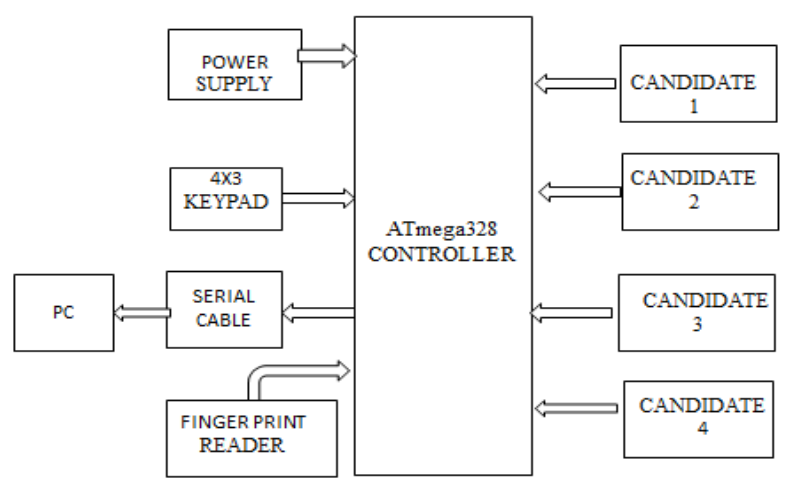

Fig.1. Block diagram

\section{ARDUINO MICROCONTROLLER}

The Arduino Uno is a microcontroller board based on the ATmega328. It has 14 digital input/output pins(of which 6 can be used as PWM outputs), 6 analog inputs, a 16MHZ crystal oscillator, a USB connection, a power jack, an ICSP header, and a reset button. It contains everything needed to support the microcontroller. It can be simply connect it to a computer with a USB cable or power it with a AC-to-DC adapter or battery to get started. The Uno differs from all precedings boards in that it does not use the FTDI USB-to-serial driver chip. Instead , it features the Atmega8U2 programmed as a USB-to-serial convertor.

\subsection{FEATURES:}

Microcontroller

Operating voltage

Input voltage(recommended)

Input voltage(limits)

Digital I/O pins

Analog input pins

DC current per I/O pin

DC current for $3.3 \mathrm{v}$ pin

Flash memory

\section{SRAM}

EEPROM

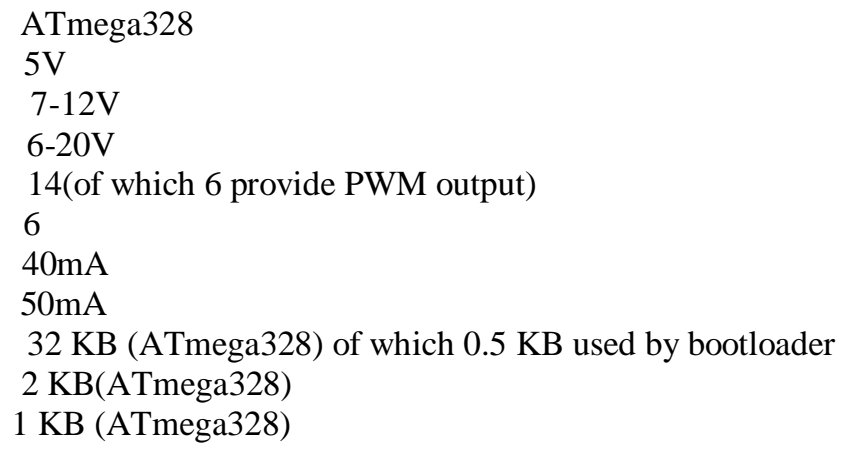

\section{ATMEGA328}

The ATmega328P is a low power CMOS 8-bit microcontroller based on AVR enhanced RISC architecture. By executing powerful instructions in a single clock cycle, ATmega328P achieves throughputs approaching 1 MIPS per MHZ allowing the system designer to optimize power consumption versus processing speed. 


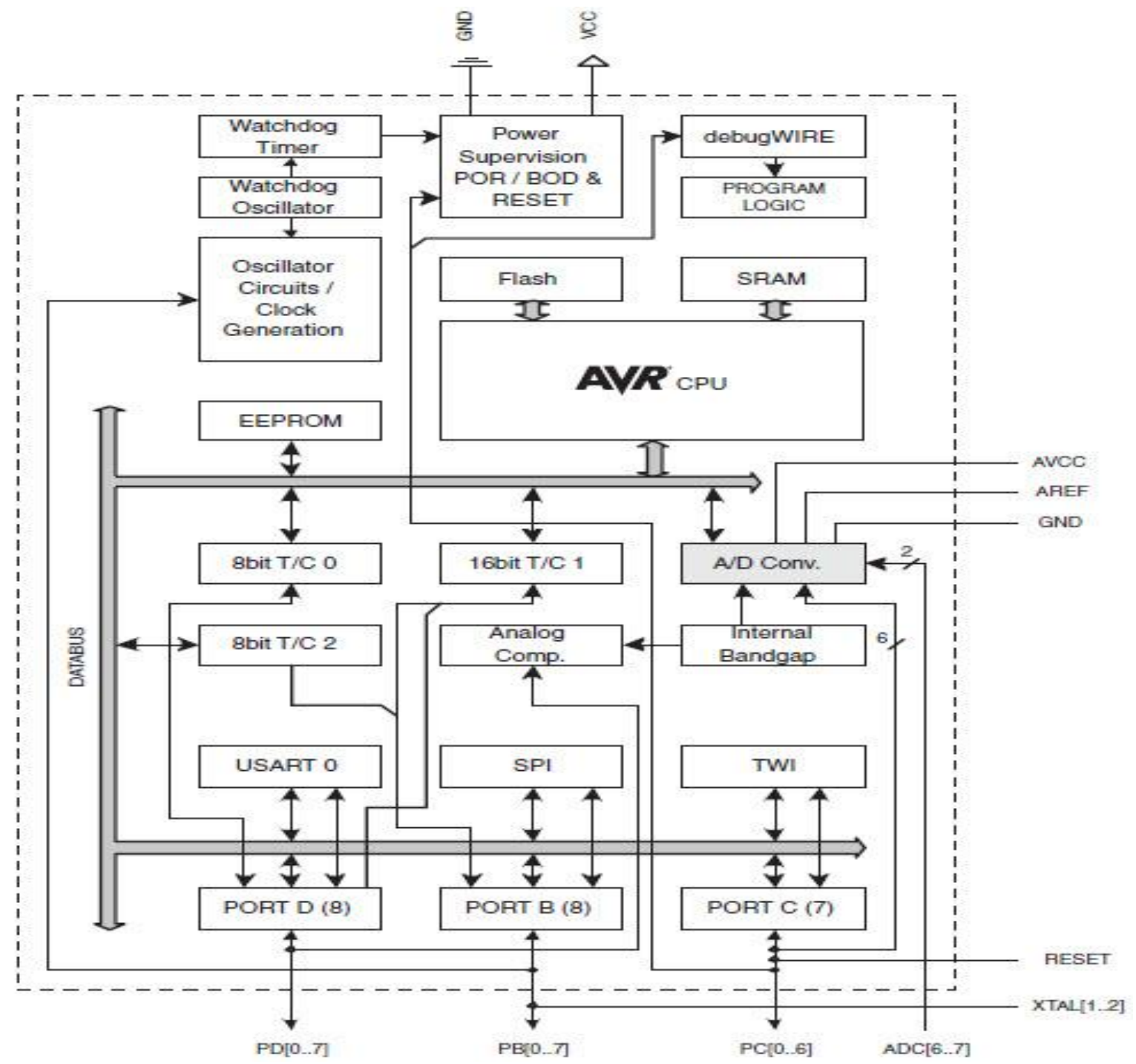

Fig.2. Architecture of ATmega328

\subsection{FEATURES}

- High performance

- Advanced RISC architecture

D Most single clock cycle execution.

Up to 20 MIPS throughput at 20MHZ.

- High endurance non volatile memory segments

\subsection{PERIPHERAL FEATURES}

- Two 8-bit timer/counters with separate prescalar and compare mode

- Real time counter with separate oscillator

- Programmable serial USART.

- Master slave SPI serial interface

- On-chip analog comparator

\subsection{SPECIAL MICROCONTROLLER} FEATURES

- External and internal interrupt sources.

- Six sleep modes: idle,ADC noise reduction, power-save, standby and extended standby.

- $\mathrm{I} / \mathrm{O}$ and packages : 23 programmable I/O lines

- Operating voltage $: 1.8-5.5 \mathrm{v}$

- Speed grade: $0=20 \mathrm{~Hz}$

- Low power consumption at $1 \mathrm{MHz}$

- Active mode : $0.2 \mathrm{ma}$

- Power down mode : $0.1 \mu \mathrm{A}$

- Power save mode : $0.75 \mu \mathrm{A}$ 


\section{PIN DIAGRAM:}

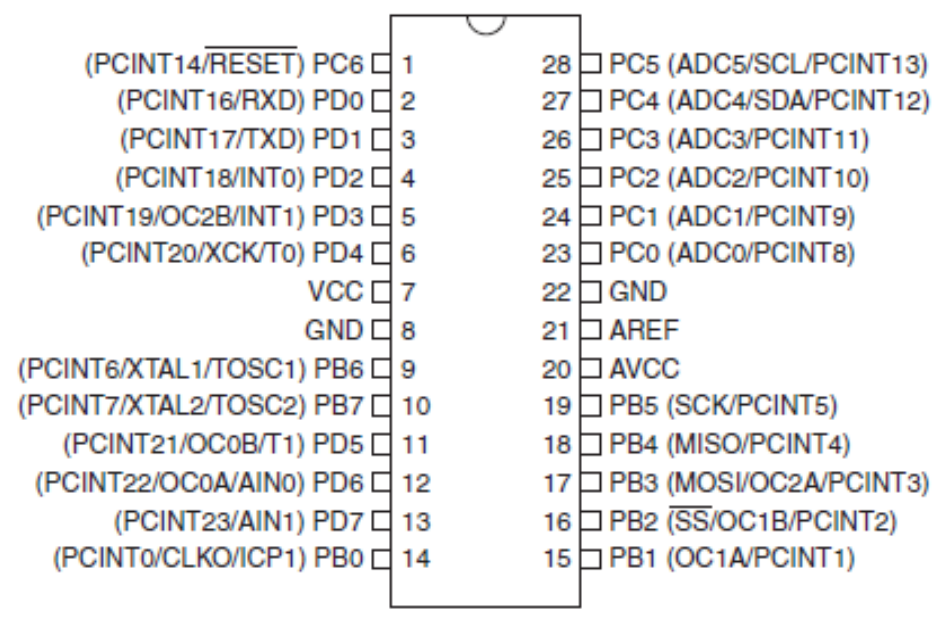

Fig.3 Pin diagram of ATmega328

\subsection{PIN DESCRIPTIONS}

VCC:Digital supply voltage

GND: ground

PORT B (PB7:0):

Port B is an 8-bit bi-directional I/O port with internal pullup resistors (selected for each bit). The port B output buffers have symmetrical drive characteristics with both high sink and source capability. As inputs, port B pins that are externally pulled low source current if the pull-up resistors are activated. The port B pins are tristated when a reset condition becomes active, even if the clock is not running.

PORT C (PC5:0):

Port $\mathrm{C}$ is a 7 bit bi-directional $\mathrm{I} / \mathrm{O}$ ports with internal pull-up resistors. The PC5:0 output buffers have symmetrical drive characteristics with both high sink and source capability as inputs, port $\mathrm{C}$ pins that are externally pulled low will source current if the pull-up resistors are activated. The port $\mathrm{C}$ pins are tri-stated when a reset condition becomes active, even if the clock is not running.

PC6/RESET:

If the RSTDISBL fuse is programmed, PC6 is used as an I/O pin. The electrical characteristics of PC6 differ from those of the other pins of port.

If the RSTDISBL fuse is unprogrammed, PC6 is used as a reset input. A low level on this pin for longer than minimum pulse length will generate a reset, even if the clock is not running.

PORT D(PD7:0):

Port $\mathrm{D}$ is an 8-bit bi-directional $\mathrm{I} / \mathrm{O}$ port with internal pull-up resistors.

AVCC:

AVCC is the supply voltage pin for the A/D Converter, PC3:0, and ADC7:6. It should be externally connected to VCC, even if the ADC is not used. If the ADC is used, it should be connected to VCC through a low-pass filter. Note that PC6..4 use digital supply voltage, VCC.

AREF:

AREF is the analog reference pin for the A/D Converter.

ADC7:6 (TQFP and QFN/MLF Package Only)

In the TQFP and QFN/MLF package, ADC7:6 serve as analog inputs to the A/D converter. These pins are powered from the analog supply and serve as 10-bit ADC

\subsection{POWER SUPPLY UNIT:}

Power supply is a very important part of electronic circuit this circuit required fixed $+5 \mathrm{~V}$ supply so to fix this voltage we needed voltage regulator. In this work used 7805 Voltage regulator which output fixed +5 volt. A voltage regulator generates a fixed output voltage of a preset magnitude that remains constant regardless of changesto its input voltage or load conditions .we are using a step down transformer to providing a necessary supply for the electronic circuits thereby voltage is step down from $230 \mathrm{v}$ ac into $12 \mathrm{v}$ ac. 


\section{CIRCUIT DIAGRAM}

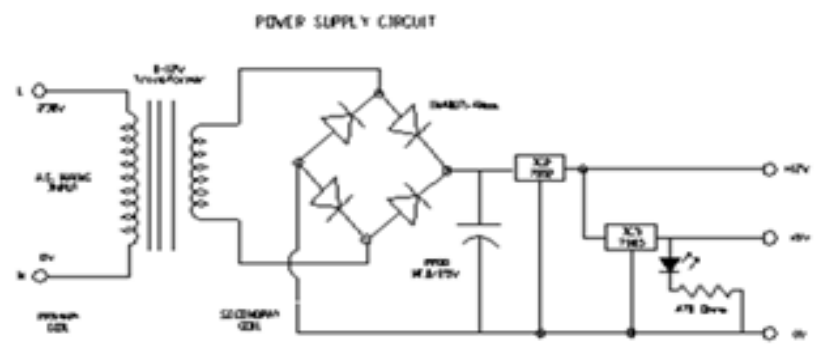

Fig .4.Circuit diagram of power supply

\section{FINGERPRINT MODULE}
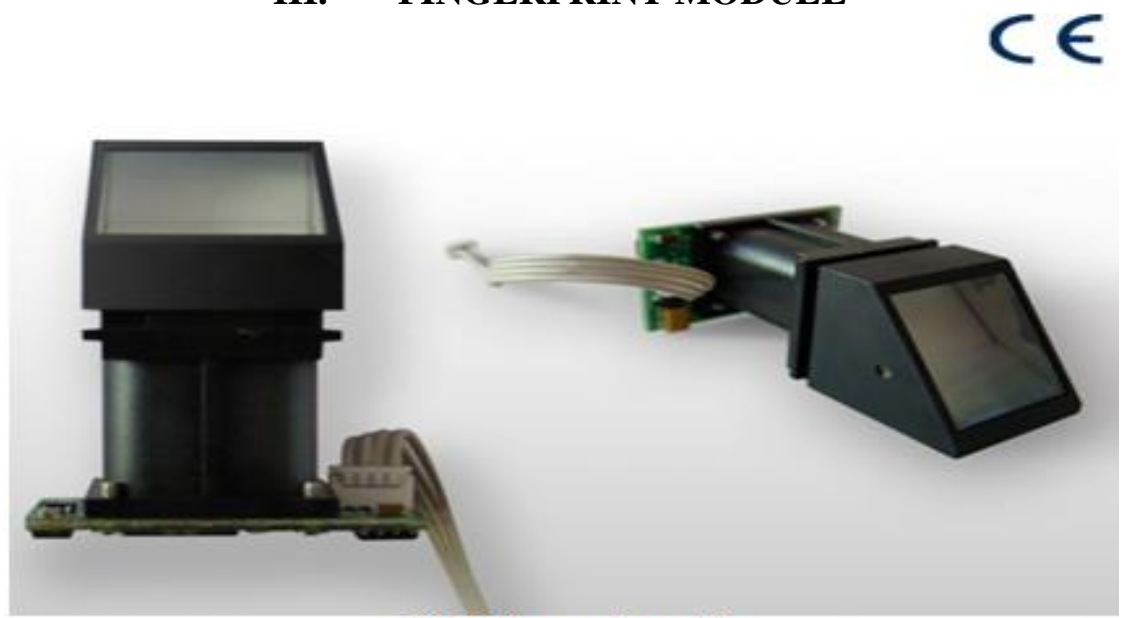

Fig 5. Finger print module

\subsection{OPERATING PRINCIPLE:}

Finger print processing includes 2 parts

- Finger print enrollment

When enrolling, user needs to enter the finger two times. The system will process the two time finger images, generate a template of the finger based on processing results and store the template.

- Finger print matching $(1: 1$ or $1: \mathrm{N})$

When matching, user enters the finger through optical sensor and system will generate a template of the finger and compare it with templates of the finger library.

TABLE 1.SPECIFICATION

\begin{tabular}{|c|c|c|c|}
\hline Power & DC 3.6V-6.0V & Interface & $\begin{array}{ll}\text { UART(TTL logic } \\
\text { level)/ USB } 1.1\end{array}$ \\
\hline Working current & $\begin{array}{l}\text { Typical: } 100 \mathrm{~mA} \\
\text { Peak: } 150 \mathrm{~mA}\end{array}$ & Matching Mode & $1: 1$ and $1: N$ \\
\hline Baud rate & $\left(9600^{\circ} \mathrm{N}\right) \mathrm{bps}$, & $\begin{array}{l}\text { Character file size } \\
\begin{array}{lllll}= & 1 & 1 & 2 \\
N & = \\
\text { (default } & & & \\
\end{array}\end{array}$ & $\begin{array}{l}256 \text { bytes } \\
N=6\end{array}$ \\
\hline Image acquiring time & $=0.55$ & Template size & 512 bytes \\
\hline Storage capacity & 256 & Security level & $5(1,2,3,4,5$ (highest $))$ \\
\hline FAR & $=0.001 \%$ & FRR & $=0.1 \%$ \\
\hline Average searching time & Els $(1: 1000)$ & Window dimension & $18 \mathrm{~mm}^{*} 22 \mathrm{~mm}$ \\
\hline Working environment & $\begin{array}{l}\text { Temp: }-10-+40 \\
\text { RH: } 40 \%-85 \%\end{array}$ & Storage environment & $\begin{array}{l}\text { Temp: }-40 \text { to }+85 \\
\text { RH: }<85 \%\end{array}$ \\
\hline Outline Dimention & Split type & \begin{tabular}{|l|} 
Module: $32^{8} 23^{8} 7 \mathrm{~mm}$ \\
Sensor: $56^{*} 20^{*} 21.5 \mathrm{~mm}$ \\
$54.5^{*} 20.6^{*} 23.8 \mathrm{~mm}$
\end{tabular} & \\
\hline
\end{tabular}




\subsection{BUFFER}

There are an image buffer and two 512-byte-character-file buffer within the RAM space of the module.

Image buffer:

Image Buffer serves for image storage and the image format is $256 * 288$ pixels.

Character file buffer :

Character file buffer, CharBuffer1, CharBuffer2, can be used to store both character file and template file.

\section{VISUAL BASICS}

Visual Basic is a third-generation event-driven programming language . Microsoft intends Visual Basic to be relatively easy to learn and use. Visual Basic was derived from BASIC and enables the rapid application development (RAD) of graphical user interface (GUI) applications, access to databases using Data Access Objects.A programmer can create an application using the components provided by the Visual Basic program itself.

\subsection{ADVANTAGES:}

- VB is used as a front end tool.

- It is easy for hardware interfacing.

- It has user friendly environment.

- It provides graphical user interface

\section{VB PROGRAMMING}

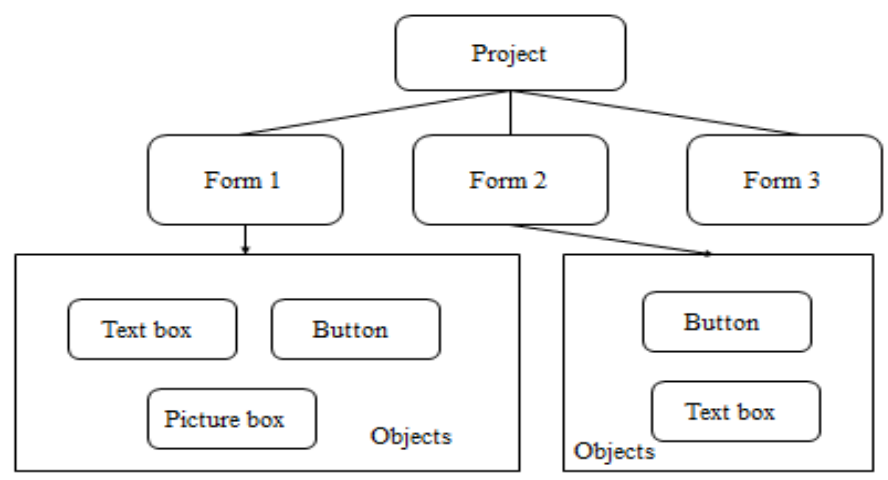

Fig. 7 Visual basics

\section{DATA PACKAGE FORMAT}

When communicating, the transferring and receiving of command/data/result are all wrapped in data package format.

TABLE 2. DATA PACKAGE FORMAT

\begin{tabular}{|l|c|c|c|c|c|}
\hline Header & Adder & $\begin{array}{c}\text { Package } \\
\text { identifier }\end{array}$ & $\begin{array}{c}\text { Package } \\
\text { Length }\end{array}$ & $\begin{array}{c}\text { Package content } \\
\text { (instruction/data/Parameter }\end{array}$ & Checksum \\
\hline
\end{tabular}

TABLE 3.COMMAND PACKAGE FORMAT

\begin{tabular}{|c|c|c|c|c|c|c|}
\hline 2 bytes & 4 bytes & 1 byte & 2 bytes & 1 byte & 1 byte & 2 bytes \\
\hline Header & $\begin{array}{c}\text { Module } \\
\text { Address }\end{array}$ & $\begin{array}{c}\text { Package } \\
\text { identifier }\end{array}$ & $\begin{array}{c}\text { Package } \\
\text { Length }\end{array}$ & $\begin{array}{c}\text { Instruction } \\
\text { Code }\end{array}$ & $\begin{array}{c}\text { Buffer } \\
\text { number }\end{array}$ & Checksum \\
\hline 0xEF01 & Xxxx & $01 \mathrm{H}$ & $04 \mathrm{H}$ & $02 \mathrm{H}$ & BufferID & sum \\
\hline
\end{tabular}




\section{TO GENERATE TEMPLATE}

Description: To combine information of character files from CharBuffer1 and CharBuffer2 and generate a template which is stored back in both CharBuffer1 and CharBuffer2. Input Parameter Return Parameter

Instruction code: $05 \mathrm{~h}$

TABLE4.COMMAND PACKAGE FORMAT

\begin{tabular}{|l|l|l|l|l|l|}
\hline Header & $\begin{array}{l}\text { Module } \\
\text { Address }\end{array}$ & $\begin{array}{l}\text { Package } \\
\text { identifier }\end{array}$ & $\begin{array}{l}\text { Package } \\
\text { length }\end{array}$ & $\begin{array}{l}\text { Instruction } \\
\text { Code }\end{array}$ & Checksum \\
\hline 0xEF01 & Xxxx & $01 \mathrm{H}$ & $03 \mathrm{H}$ & $05 \mathrm{H}$ & $09 \mathrm{H}$ \\
\hline
\end{tabular}

TABLE5.ACKNOWLEDGE PACKAGE FORMAT

\begin{tabular}{|c|c|c|c|c|c|}
\hline 2 bytes & 4 bytes & 1 byte & 2 bytes & 1 byte & 2 bytes \\
\hline Header & $\begin{array}{c}\text { Module } \\
\text { Address }\end{array}$ & $\begin{array}{c}\text { Package } \\
\text { Identifier }\end{array}$ & $\begin{array}{c}\text { Package } \\
\text { length }\end{array}$ & $\begin{array}{c}\text { Confirmation } \\
\text { Code }\end{array}$ & Checksum \\
\hline 0xEF01 & $\mathrm{Xxxx}$ & $07 \mathrm{H}$ & $03 \mathrm{H}$ & $\mathrm{XxH}$ & sum \\
\hline
\end{tabular}

Note: Confirmation code $=00 \mathrm{H}$ : operation success;

Confirmation code $=01 \mathrm{H}$ : error when receiving package;

Confirmationcode $=0 \mathrm{aH}$ :fail to combine the character files. That'sthe character files don't belong to one finger.

\section{RESULTS}

Election officer must enter the password and the corresponding state of the voters for verification.

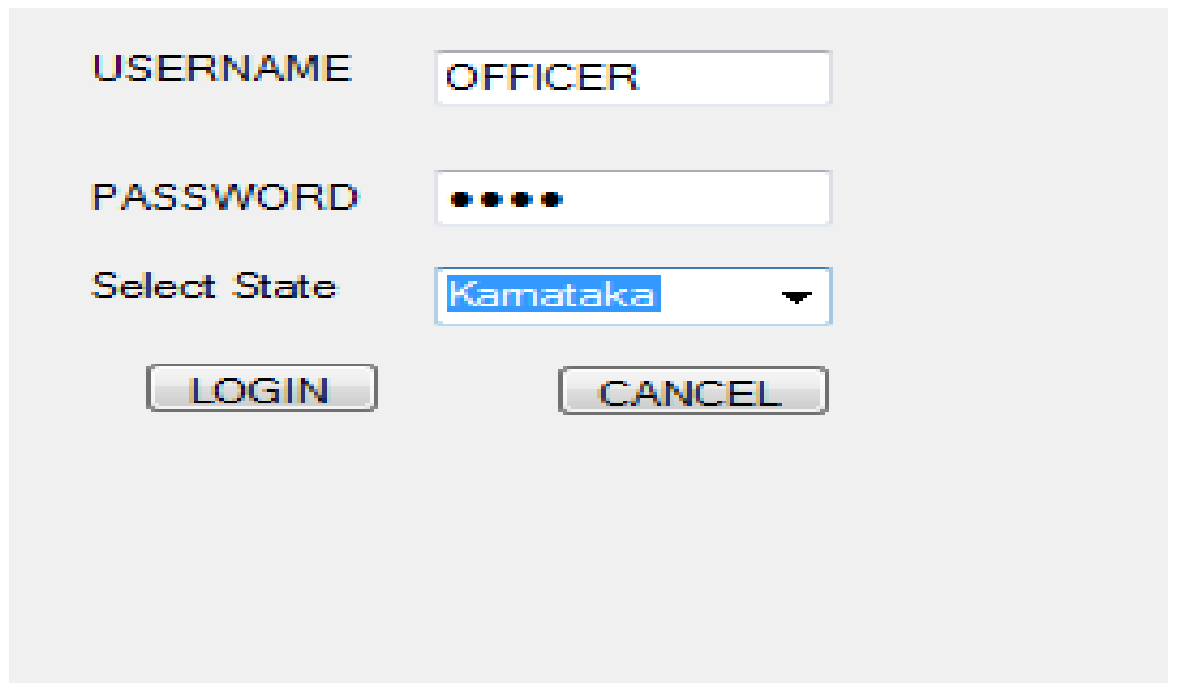

After login voter must authenticate it for security purpose. 
If the voter belong to that state then the person details will be displayed in a system which is already stored in databases.

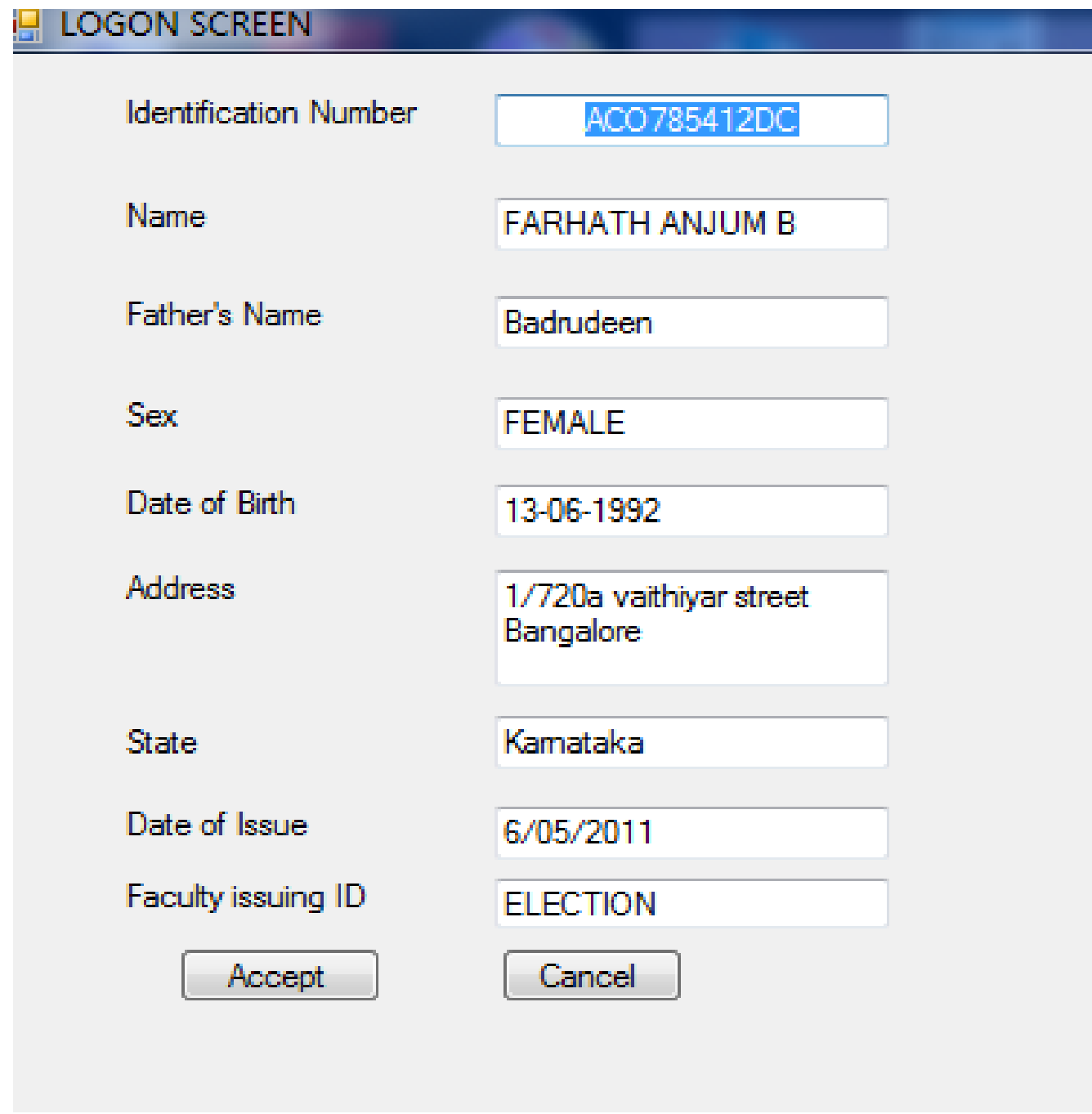


If the details are correct then voter must accept it. After then election symbol of the particular state will be displayed.

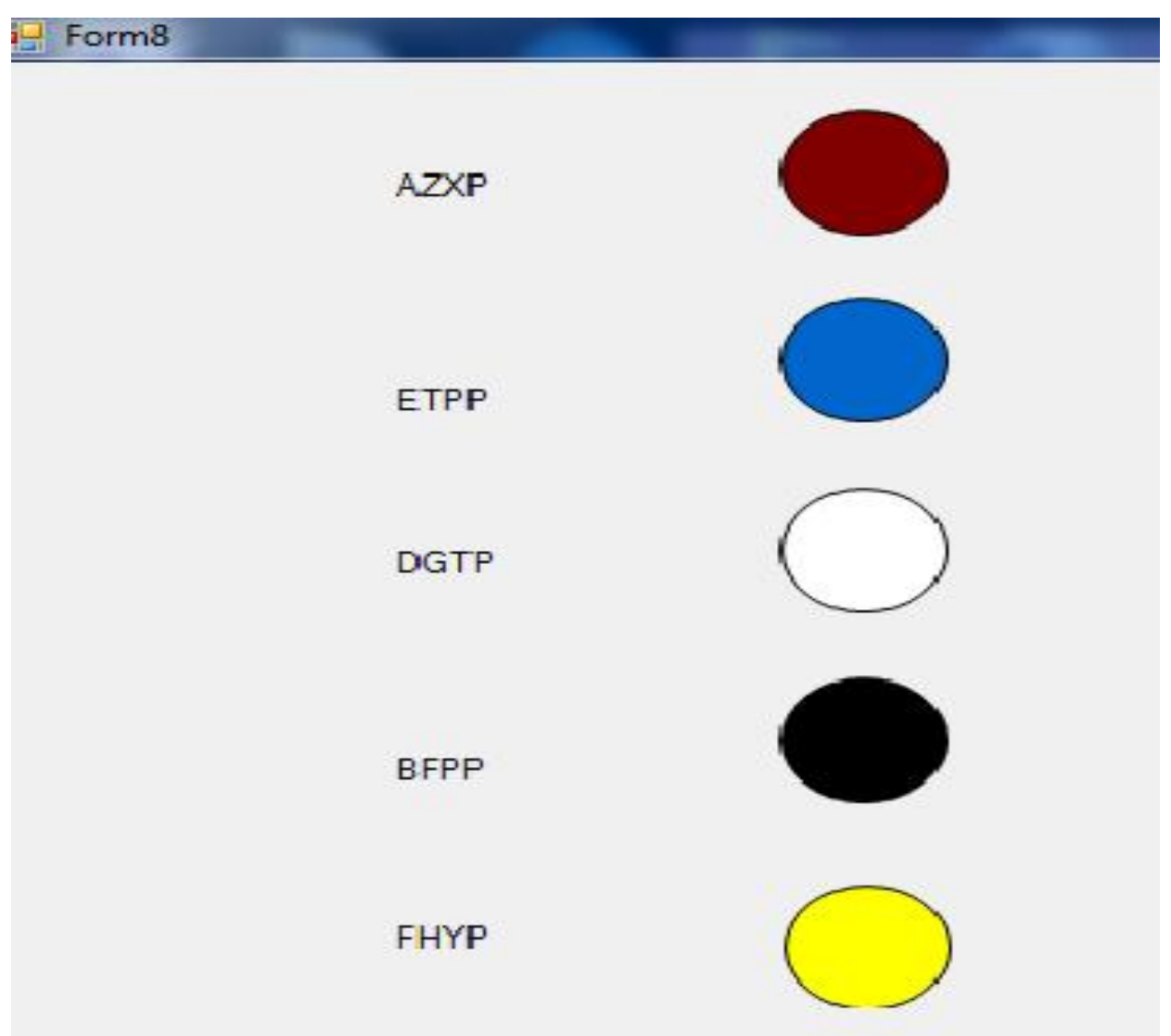

Voters can select the symbol andcast their votes to the particular party.

After polling results are stored in the databases.

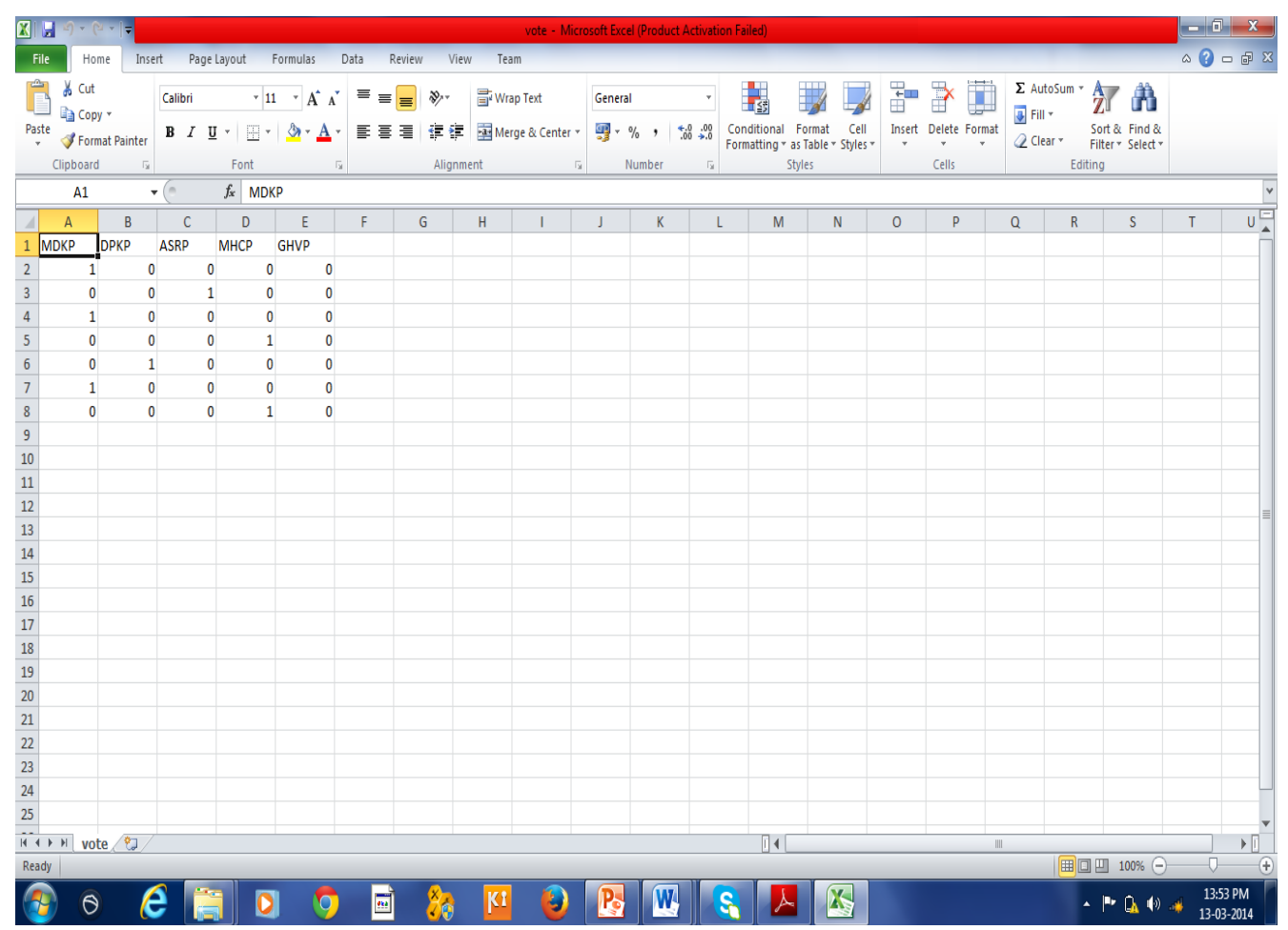


Similarly for another state,
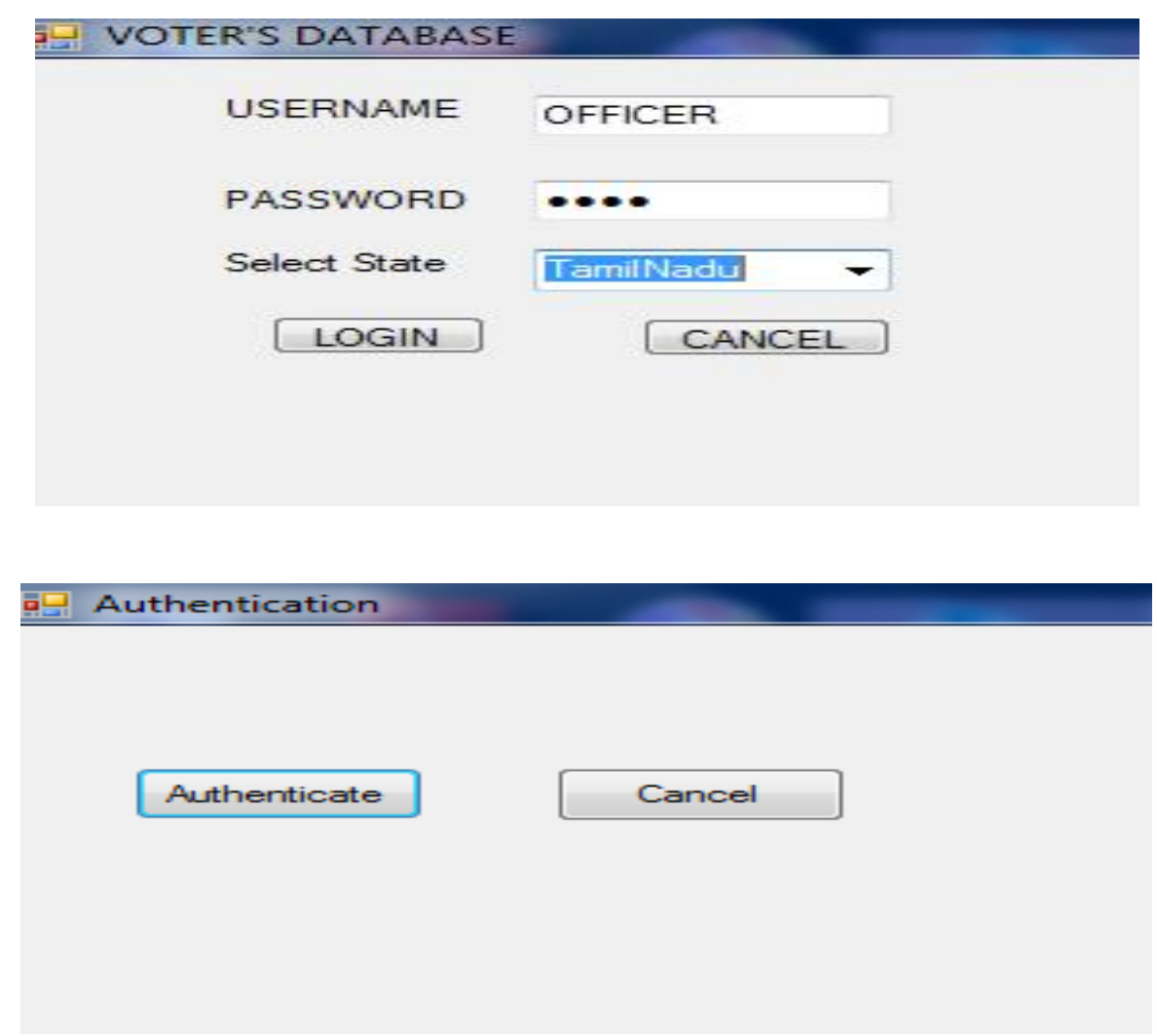

\section{VOTER'S DATABASE}

Identification Number

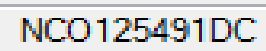

Name

\section{DEEPA.M}

Father's Name

Murugan

Sex

FEMALE

Date of Birth

17-08-1993

Address

73. veraiyur.

Thiruvannamalai

Label1

TamilNadu

Date of Issue

$6 / 05 / 2012$

Faculty issuing ID

ELECTION

Accept

Cancel 

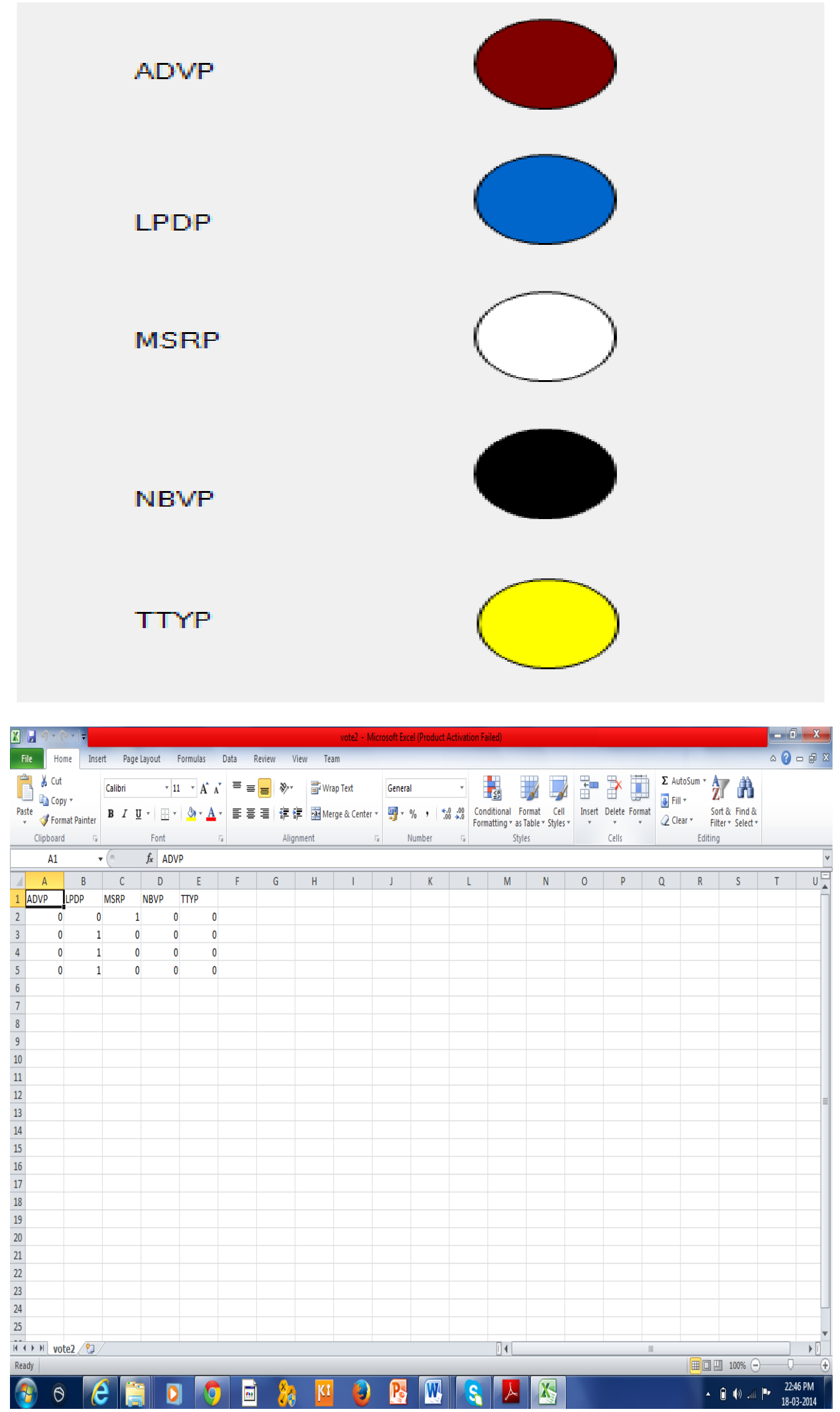


\section{CONCLUSION}

In olden days, polling is done more manually using ballot boxes and papers. As the world got modernized and automation came in to effect, it has been changed to Electronic Voting Machines. Bio-metric EVM may be considered as its updation. Yet more improvements can be made as science advances. Memory of finger print module can be expanded.We can use a $1 \mathrm{mb}$ flash memory finger print module for increasing the capacity.External memory can be provided for storing the finger print image, which can be later accessed for comparison.Smart Card reader module is supposed to be introduced with the existing module for further security, and to reduce the database storage. Audio output can be introduced to make it user friendly for illiterate voters.Retina scanning can also be developed.

\section{REFERENCES}

[1] Diponkar Paul and Sobuj Kumar Ray, "A Preview on microcontroller based electronic voting machine" ,International Journal Of Information And Electronics Engineering, Vol.3, No.2, March 2013.

[2] Sanjay Kumar and Manpreeth Singh, "Design a secure electronics voting system using finger print technique “,(IJCSI) International Journal Of Computer Science Issues, Vol.10, Issue 4, No.1, July 2013.

[3] Gomathi.B and VeenaPriyadarshini.S, "Modernised voting machine using finger print recognition " ,International Journal Of Scientific And Engineering Research , Vol.4, Issue 5, May 2013

[4] Alaguvel.R , Gnanavel.G and Jagadhambal.K , "Biometrics using Electronic Voting System With Embedded Security“, International Journal Of Advanced Research In Computer Engineering And Technology(IJARCET)Vol 2, Issues 3, March 2013

[5] Kumar, " Electronic voting machine- A review", IEEE International Conference on Pattern Recognition, Informatics and Medical Engineering (PRIME),2012.

[6] S. Kumar and E.Walia, "Analysis of Electronic Voting system in Various Countries", International Journal on Computer Science and Engineering, vol. 3(5), 1825-1830, 2011.

[7] https://en.wikipedia.org/wiki/electronic_voting

[8] en.wikipedia.org/wiki/finger_print_module

[9] A study on visual basics. 